\title{
Proses elektroplating nikel dengan variasi jarak anoda katoda dan tegangan listrik pada baja ST-41
}

\author{
Billy Permadi ${ }^{1}$, Asroni ${ }^{2}$, Eko Budiyanto ${ }^{3}$ \\ Prodi Teknik Mesin, Fakultas Teknik, Universitas Muhammadiyah Metro ${ }^{1}$ \\ Jl. Ki Hajar Dewantara 15 A Kota Metro, Lampung, Indonesia \\ Jurusan Teknik Mesin, Fakultas Teknik, Universitas Muhammadiyah Metro ${ }^{2,3}$ \\ Jl. Ki Hajar Dewantara 15 A Kota Metro, Lampung, Indonesia \\ ${ }^{*}$ Corresponding author: asroni14@yahoo.com
}

\begin{abstract}
Electroplating process is a coating process where the deposition of a thin metal coating occurs on a coated surface using direct current and constant voltage. The process of finishing metal products uses Nickel as a coating that serves to improve the properties of the metal so that it resists corrosion and attach importance to the appearance of the metal surface. The metal coating process is carried out by electroplating technique with Nickel which occurs as an anode, and electrolyte uses in this process contained Nickel Sulphate. This study aims to determine the effect of distance variations and electrical pressure on layer thickness and adhesive strength. Anode Material coated with ST-41 Steel Plate with dimensions of $70 \times 25 x$ $20 \mathrm{~mm}$. While the cathode uses nickel (Ni) with dimensions of $10 \times 20 \times 20 \mathrm{~mm}$. Cathode distance variations with anodes 5,10 , and $15 \mathrm{~cm}$ and electrical voltage variations of 3.5 Volts, 5 Volts, and 7.5 Volts. Bath time of 40 minutes and adhesion testing using the Posi Test AT-M Adhesion Tester. The results obtained from this study are the distance of the cathode with the best anode found at a distance of $5 \mathrm{~cm}$ and a voltage of 7.5 volts with a thickness of 0.0160 $\mathrm{mm}$. Then the best voltage is at 7.5 Volts with a sticky strength value of > $21.53 \mathrm{MPa}$.
\end{abstract}

Keywords: Electroplating, Nickel, Anode, Cathode, ST-41 Steel.

\begin{abstract}
Abstrak
Proses elektroplating adalah proses pelapisan dimana terjadi pengendapan suatu pelapis logam tipis pada permukaan yang dilapisi menggunakan arus listrik searah dan tegangan yang konstan. Proses finishing produk logam menggunakan Nikel sebagai pelapis yang berfungsi untuk memperbaiki sifat logam agar tahan korosi dan memperindah penampilan permukaan logam. Proses pelapisan logam ini dilakukan dengan teknik elektroplating dengan Nikel yang bertindak sebagai anoda, sedangkan benda yang dilapisi tersebut dicelupkan dalam suatu elektrolit yang mengandung Nikel Sulfat. Tujuan dari penelitian adalah untuk mengetahui pengaruh variasi jarak dan teagangan listrik terhadap ketebalan lapisan dan kuat rekat. Anoda Bahan yang dilapisi Baja Plat ST-41 dengan dimensi 70 × 25 x 20 mm. sedangkan katoda menggunakan nikel (Ni) dengan dimensi $10 \times 20 \times 20 \mathrm{~mm}$. Variasi jarak katoda dengan anoda 5,10 , dan $15 \mathrm{~cm}$ dan variasi tegangan listrik 3,5 Volt, 5 Volt, dan 7,5 Volt. Waktu celup 40 menit dan pengujian kerekatan menggunakan PosiTest AT-M Adhesion Tester. Hasil yang di dapat dari peneltian ini yaitu jarak katoda dengan anoda yang terbaik ditemukan pada jarak 5 $\mathrm{cm}$ dan tegangan 7,5 Volt dengan ketebalan 0,0160 $\mathrm{mm}$. Kemudian tegangan terbaik yaitu pada 7,5 Volt dengan nilai kuat rekat sebesar >21,53 MPa.
\end{abstract}

Kata kunci: Elektroplating, nikel, anoda, katoda, baja ST-41.

\section{Pendahuluan}

Kehidupan masyarakat Indonesia khususnya di Provinsi Lampung tepatnya di
Kota Metro dalam kondisi moderen ini tidak terlepas dari yang namanya teknologi dalam bidang teknik dan masih banyak lagi 
inovasi yang belum terselesaikan hingga saat ini dalam pencapaiannya untuk membuat benda-benda dengan menggunakan proses elektroplating. " $D i$ kota metro ini masih sangat susah bahkan belum ditemukan jasa yang menyediakan pelapisan menggunakan proses elektroplating secara langsung" pendapat ini didapat karena penulis telah melakukan survei dari sepuluh bengkel di sudut-sudut Kota Metro dari penjuru barat, timur, selatan, utara dan Metro Pusat pada tahun 2019, tentunya hal ini sangat menyulitkan bagi kebutuhan masyarakat di Kota Metro supaya bagaimana material-material yang digunakan dalam kebutuhan seperti aksesoris, komponen-komponen dekorasi seperti spare part motor, mobil dan masih banyak lagi alat-alat berjenis baja karbon rendah khususnya baja "ST41" yang proses pengerjaan akhirnya (finishing) belum banyak menggunakan proses elektroplating/pelapisan dengan listrik. Dan apabila masyarakat Kota Metro ingin melakukan pelapisan listrik seperti krom, nikel, tembaga dll maka mereka akan mengirimkan bahan meterial tersebut ke luar wilayah Kota Metro.

\section{Tinjauan Pustaka}

\section{Elektroplating}

Proses elektroplating adalah proses pelapisan dimana terjadi pengendapan suatu pelapis logam tipis pada permukaan yang dilapisi menggunakan arus listrik searah dan tegangan yang konstan [1]. Proses finishing produk logam menggunakan Nikel sebagai pelapis yang berfungsi untuk memperbaiki sifat logam agar tahan korosi dan dan memperindah penampilan permukaan logam. Proses pelapisan logam ini dilakukan dengan teknik elektroplating dengan Nikel yang bertindak sebagai anoda, sedangkan benda yang dilapisi tersebut dicelupkan dalam suatu elektrolit yang mengandung Nikel Sulfat [2].

Faktor-faktor yang mempengaruhi elektroplating yaitu:

a. Kerapatan Arus
Kecepatan arus yang baik adalah arus yang tinggi pada saat arus diperkirakan masuk, bagaimanapun nilai kerapatan arus mempengaruhi waktu plating untuk mencapai ketebalan yang diperlukan.

b. Voltase (tegangan)

Tegangan merupakan salah satu faktor terpenting dalam proses elektroplating karena mempengaruhi penguraian ionion logam menjadi logam yang menempel pada benda kerja yang dilapisi.

c. Suhu

Suhu sangat penting untuk menyeleksi kecocokan jalannya reaksi dan melindungi pelapisan. Keseimbangan suhu ditentukan oleh beberapa faktor seperti ketahanan, jarak anoda dan katoda, serta kuat arus yang digunakan. [3]

\section{Nikel}

Nikel merupakan salah satu bahan tambang mineral logam dengan lambang unsur Ni. Unsur Ni sangat reaktif dengan oksigen sehingga keberadaan nikel di alam berupa senyawa. Walaupun nikel bersifat reaktif terhadap oksigen, akan tetapi tidak mengalami korosi, sehingga mempunyai peranan penting dalam industri baja. Campuran nikel dengan krom dan besi menghasilkan baja tahan karat yang biasa disebut baja nirkarat (stainless steel).

Nikel (Ni) adalah logam yang mempunyai sifat fisik antara lain berwarna putih mengkilat, sangat keras, tidak berkarat dan tahan terhadap asam encer. Oleh karena itu penggunaannya banyak diperuntukan untuk melapisi barang yang terbuat dari besi, tembaga dan baja karena nikel mempunyai sifat keras, tahan korosi dan mudah mengkilat bila digosok. Selain itu, nikel digunakan juga untuk membuat baja nirkarat dan alloy atau campuran nikel dengan tembaga atau beberapa logam lain yang penting untuk industri. Beberapa contoh alloy adalah Monel, yaitu campuran nikel dengan tembaga dan besi $(\mathrm{Ni}, \mathrm{Cu}, \mathrm{Fe})$ digunakan untuk membuat instrumen transmisi listrik, Nikrom $(\mathrm{Ni}, \mathrm{Fe}, \mathrm{Cr})$ 
digunakan sebagai kawat pemanas, dan Alniko ( $\mathrm{Al}, \mathrm{Ni}, \mathrm{Fe}, \mathrm{Co}$ ) digunakan untuk membuat magnet [4].

\section{Baja}

Logam baja merupakan material konstruksi yang seringkali diaplikasikan pada berbagai macam struktur karena memilki sifat mekanik yang baik serta mudah difabrikasi. Namun, struktur yang dibuat dari logam baja lebih cepat mengalami korosi dan fouling sehingga menimbulkan kerugian baik sifatnya langsung maupun tidak langsung yang mencapai 5\% dari GNP (Gross National Product). Oleh karena itu, mengendalikan laju korosi pada logam atau paduannya menjadi hal yang penting. Selama proses korosi, logam murni cenderung akan kembali pada keadaan sebagaimana sama dengan keadaan bijih logamnya [5].

\section{Metode Penelitian}
Alat
1) Power Supply
2) Multitester
3) Stopwatch
4) Mikrometer
5) Gerindra
6) Amplas
7) Posi Test AT-M Adhesion Tester

\section{Bahan}

1) Amplas

2) Baja Plat ST41

3) Logam Nikel

4) Nikel Sulfat (NiSO4)

5) Larutan Asam Sulfat (H2SO4)

6) Kabel

7) Aquades

\section{Prosedur Penelitian}

1) Mempersiapkan Wadah penampung sebagai media elektroplating.

2) Mempersiapkan bahan-bahan uji dari logam Nikel (anoda) dan baja karbon rendah (katoda).

3) Mempersiapkan larutan elektrolit Asam Sulfat $\left(\mathrm{H} 2 \mathrm{SO}_{4}\right)$.

4) Pembuatan bahan uji baja karbon rendah dan logam nikel lalu, memotong dengan ukuran tinggi $70 \mathrm{~mm}$, lebar 25 $\mathrm{mm}$, tebal $20 \mathrm{~mm}$.

5) Membersihkan dan menghaluskan permukaan bahan uji menggunakan gerinda, amplas, dan kain lap.

6) Mengukur ketebalan bahan uji gunanya untuk mengetahui sebelum pengujian dilakukan.

7) Merendam atau mencelupkan bahan uji dengan menggunakan larutan air bersih.

8) Keringkan bahan uji dengan cara membiarkan bahan uji kering dengan sendirinya.

9) Menghubungkan baja karbon rendah (katoda) pada arus listrik negatif.

10) Menyiapkan larutan elektrolit $20 \mathrm{ml}$ asam sulfat (H2SO4), 800 gr nikel sulfat (NiSO4) serta 2 liter Aquades dan aduk hingga larutan tercampur dan merata.

11) Masukkan elektrolit ke dalam wadah sampai katoda dan anoda terendam secara baik.

12) Mengatur jarak katoda dan anoda serta tegangan listrik DC yang telah disesuaikan.

13) Hubungkann multimeter pada saat saat tertentu ketika ingin melakukan atau memulai proses elektroplating.

14) Melakukan pengujian ketebalan dan kerekatan pada bahan uji sebelum proses elektroplating dilakukan.

15) Hidupkan daya listrik dan hubungkan ke power suplai ke katoda (-) dan anoda $(+)$

16) Mencatat waktu akan memulai penrendaman dan setelah perendaman proses elektroplating saat daya listrik dihubungkan.

17) Mengangkat bahan uji pada waktu yang telah ditentukan.

18) Membersihkan bahan uji dengan menggunakan air bersih secara mengalir dan keringkan.

19) Melakukan pengujian ketebalan dan kerekatan pada bahan uji setelah proses elektroplating dilakukan. 


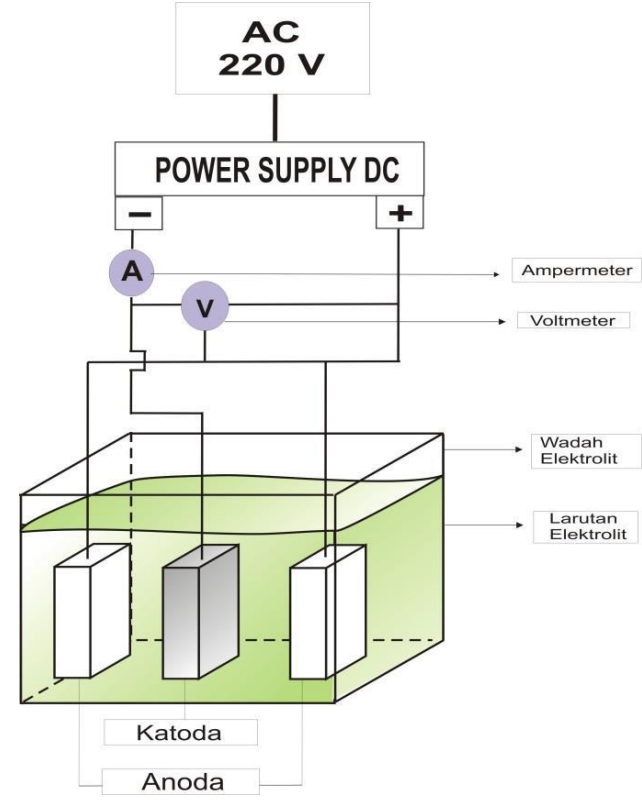

Gambar 1. Skema Elektroplating

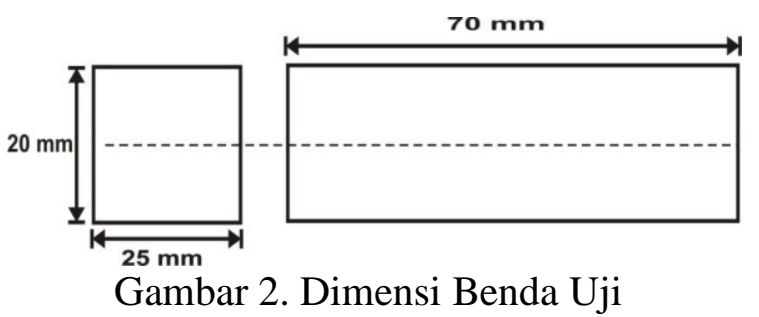

\section{Hasil dan Pembahasan}

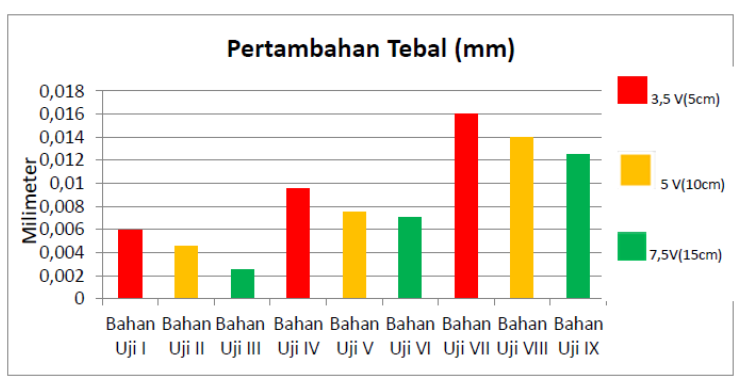

Gambar 3. Diagram pengaruh tegangan listrik dan jarak anoda katoda terhadap ketebalan lapisan

Dari diagram tersebut terlihat bahwa ketebalan optimal yang terjadi pada tegangan 3,5 Volt dan jarak anoda - katoda $10 \mathrm{~cm}$. Sedangkan ketebalan terendah terjadi pada tegangan listrik 7,5 Volt dan jarak anoda - katoda $15 \mathrm{~cm}$.

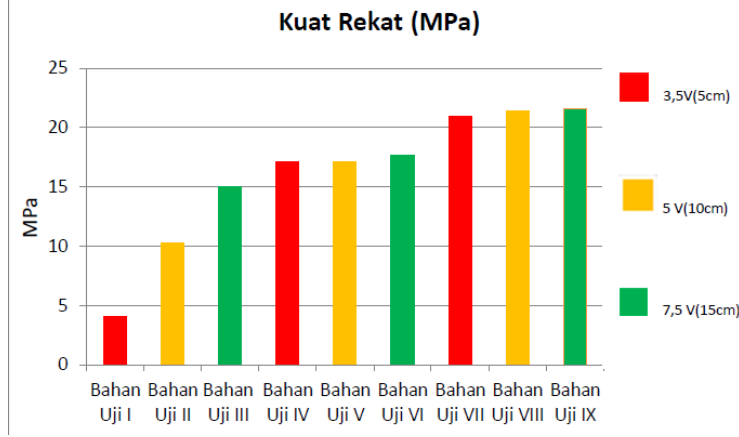

Gambar 4. Diagram pengaruh tegangan listrik dan jarak anoda dan katoda terhadap kuat rekat

Dari diagram tersebut terlihat bahwa kuat rekat optimal yang terjadi pada tegangan 7,5 Volt dan jarak anoda - katoda $15 \mathrm{~cm}$. Sedangkan kuat rekat terendah terjadi pada tegangan listrik 3,5 Volt dan jarak anoda - katoda $5 \mathrm{~cm}$.

\section{Kesimpulan}

Kesimpulan yang di dapat dari peneltian ini yaitu, variasi Jarak katoda dengan anoda yang terbaik ditemukan pada jarak $5 \mathrm{~cm}$ dan tegangan 7,5 volt dengan ketebalan 0,0160 mm. kemudian tegangan terbaik yaitu pada 7,5 volt dengan nilai kuat rekat sebesar > 21,53 Mpa.

\section{Referensi}

[1] Budiyanto, E., Setiawan, D. A., Supriadi, H., \& Ridhuan, K. (2017). Pengaruh jarak anoda-katoda pada proses elektroplating tembaga terhadap ketebalan lapisan dan efisiensi katoda baja AISI 1020. Turbo: Jurnal Program Studi Teknik Mesin, 5(1).

[2] Miaratiska, N., \& Azizah, R. (2015). Hubungan Paparan Nikel dengan Gangguan Kesehatan Kulit pada Pekerja Industri Rumah Tangga Pelapisan Logam di Kabupaten Sidoarjo. Universitas Airlangga.

[3] Nugroho, I. L. (2018). Pengaruh variasi voltase terhadap besar butir dan ketebalan pelapisan hasil elektroplating kuningan $(\mathrm{Cu}-\mathrm{Zn})$ pada baja karbon SA 516 (Doctoral 
dissertation, University of Muhammadiyah Malang).

[4] Pardiarto, B. (2013, 6 12). Nikel, Komoditas Logam Strategis. Retrieved from http://geomagz.geologi.esdm.go.id/: http://geomagz.geologi.esdm.go.id/ni kel-komoditas-logam-strategis/

[5] Setiawan, A. (2018). Sintesis dan Karakterisasi $\mathrm{ZnO}$ sebagai Coating Antikorosi $\mathrm{ZnO} / \mathrm{Al} \quad(\mathrm{OH}) \quad 3$ Pada Material Baja Karbon. TEKNIK, 39(1). 